CLINICAL STUDY

\title{
Adrenocortical carcinoma: is the surgical approach a risk factor of peritoneal carcinomatosis?
}

S Leboulleux, D Deandreis, A Al Ghuzlan ${ }^{1}$, A Aupérin ${ }^{2}$, D Goéré ${ }^{3}$, C Dromain ${ }^{4}$, D Elias ${ }^{3}$, B Caillou ${ }^{1}$, J P Travagli ${ }^{3}$, T De Baere ${ }^{4}$, J Lumbroso, J Young ${ }^{5}$, M Schlumberger and E Baudin

Department of Nuclear Medicine and Endocrine Oncology, Departments of ${ }^{1}$ Pathology, ${ }^{2}$ Statistics, ${ }^{3}$ Surgery and ${ }^{4}$ Radiology, Institut Gustave Roussy, University Paris Sud-XI, 39 Rue Camille Desmoulins, 94805 Villejuif Cedex, France and ${ }^{5}$ Service d'Endocrinologie et des Maladies de la Reproduction, Hôpital de Bicêtre, 78 Rue du Général Leclerc, University Paris Sud-XI, 94275 Le Kremlin-Bicêtre, France

(Correspondence should be addressed to S Leboulleux; Email: leboulleux@igr.fr)

\begin{abstract}
Context: Peritoneal carcinomatosis $(\mathrm{PC})$ is a rare site of distant metastases in patients with adrenocortical cancer (ACC). One preliminary study suggests an increased risk of PC after laparoscopic adrenalectomy (LA) for ACC.

Objective: The objective of the study was to search for risk factors of PC including surgical approach. Design: This was a retrospective cohort study conducted in an institutional practice.

Patients: Sixty-four consecutive patients with ACC seen at our institution between 2003 and 2009 were included. Mean tumor size was $132 \mathrm{~mm}$. Patients had stage I disease in 2 cases, stage II disease in 32 cases, stage III disease in 7 cases, stage IV disease in 21 cases, and unknown stage disease in 2 cases. Surgery was open in 58 cases and laparoscopic in 6 cases.

Main outcome: The main outcome was the risk factors of PC.

Results: PC occurred in $18(28 \%)$ patients. It was present at initial diagnosis in three cases and occurred during follow-up in 15 cases. The only risk factor of PC occurring during follow-up was the surgical approach with a 4-year rate of PC of 67\% (95\% confidence interval (CI), 30-90\%) for LA and $27 \%(95 \% \mathrm{CI}, 15-44 \%)$ for open adrenalectomy $(P=0.016)$. Neither tumor size, stage, functional status, completeness of surgery, nor plasma level of op'DDD was associated with the occurrence of PC.

Conclusion: We found an increased risk of PC after LA for ACC. Whether this is related to an inappropriate surgical approach or to insufficient experience in ACC surgery should be clarified by a prospective program.
\end{abstract}

European Journal of Endocrinology 162 1147-1153

\section{Introduction}

Peritoneal carcinomatosis (PC) in adrenocortical carcinoma (ACC) is unusual and was reported in $4-15 \%$ of the patients (1-4). Peritoneal dissemination occurs essentially through tumor cells spread across the peritoneal cavity before surgery, but it can also be caused by iatrogenic dissemination during the operation itself. Gonzalez et al. (5) reported an $8 \%$ risk of PC in patients treated through open adrenalectomy (OA) and an $83 \%$ risk of $\mathrm{PC}$ in patients treated through laparoscopic adrenalectomy (LA). Classically, OA allows a maximal exposure, a vascular control of the inferior vena cava and renal vessels, and lymphadenectomy. LA was first introduced for the resection of small, presumably benign tumors and of pheochromocytoma (6). Studies have documented its superiority over OA in terms of postoperative recovery, length of hospital stay, and overall costs (7-11). It has therefore become the treatment of choice for benign lesions with a diameter of $<6 \mathrm{~cm}$, whereas $\mathrm{OA}$ remains the standard treatment for ACC with invasion of adjacent organs, inferior vena cava thrombosis, enlarged regional lymph nodes, or tumors larger than $10-12 \mathrm{~cm}$ in size $(12,13)$. Because of the excellent results of LA, several authors proposed it for larger and malignant adrenal tumors (14-20). However, these reports derived from centers with very large experience in laparoscopic surgery included a limited number of ACC patients and had a short follow-up. The risks of tumor spillage and of local recurrence after LA for ACC remain unknown.

We therefore performed a retrospective study to search for factors associated with PC in consecutive ACC patients treated with adrenalectomy and referred to our tertiary care referral center for postoperative treatment and follow-up. 


\section{Patients and methods}

\section{Patients}

Approval from our institutional review board was obtained for the study. Files of all patients between November 2003 and April 2009 were reviewed. Inclusion criteria were as follows: i) patients treated with adrenalectomy, ii) confirmed pathological diagnosis of malignancy (defined with a Weiss score of 3 or more), and iii) postoperative imaging performed within 2 months of surgery.

At initial diagnosis, clinically functional tumors were confirmed by appropriate hormonal tests. Otherwise, biological tests included measurement of potassium level, plasma and/or urinary excretion of cortisol, plasma testosterone and/or androstenedione and/or dehydroepiandrosterone sulfate (3).

\section{Methods}

All patients underwent a postoperative thoraco-abdomino-pelvic computed tomography (TAP-CT) with i.v. injection of iodinated contrast medium (21). Complete surgery was defined by a R0 resection and a normal TAP-CT performed within 2 months after surgery. Initial staging was based on the Revised TNM Classification of the European Network for the Study of Adrenal Tumors (22). PC diagnosed within 2 months after initial surgery was considered as being present since initial diagnosis. Some patients also underwent fluorodeoxyglucose positron emission tomography (FDG-PET) either postoperatively (13 cases) or during follow-up (26 cases).

PC was diagnosed on postoperative CT in case of parietal peritoneal thickening, parietal peritoneal enhancement, and enhancing nodules (23). Recurrences in the adrenal bed, stuck to the peritoneum, were classified as local recurrences. PC on FDG-PET/CT was suspected in cases of intense peritoneal focal uptake, nodular or curvilinear uptake along the liver or left subphrenic space (23). All PC diagnosed on FDG-PET were confirmed on a subsequent guided TAP-CT. All PC diagnosed on CT and on FDG-PET/CT were confirmed by one experienced radiologist and one experienced nuclear medicine physician respectively. The standard basis for diagnosis of PC was confirmed by tumor pathology in four cases and by progression on follow-up TAP-CT in the other cases.

\section{Statistical analysis}

The time to PC was defined as the time between surgery and occurrence of PC or last follow-up for patients who did not experience PC. Time to PC and time to local relapse were estimated with the Kaplan-Meier method. The 95\% confidence intervals (95\% CIs) of the actuarial rates were calculated using the Rothman method (24).
Risk factor analysis was performed by log-rank test with the following parameters: type of surgery (OA versus LP), completeness of resection, tumor size $(\leq 5 \mathrm{~cm}$, $5-10 \mathrm{~cm}$, or $>10 \mathrm{~cm}$ ), stage, and functional status. The occurrence of PC was compared between patients who received op'DDD with effective therapeutic plasma levels and those who did not reach effective therapeutic level or who did not receive op'DDD at all. Because obtaining the therapeutic level was not a baseline characteristic but occurred during follow-up, analysis was performed using a Cox's model with the achievement of therapeutic level as a time-dependent covariate.

\section{Results \\ Patients}

Seven patients were excluded because of unknown surgical procedure (two cases), absence of adrenal surgery due to large tumor burden with distant metastases (one case), and absence of postoperative imaging study (four cases). Functioning tumors were identified in 35 patients $(55 \%)$, among whom 18 disclosed mixed hormone productions. Sixty-four patients (28 males and 36 females; median age: 54 years; range: 23-79) were therefore included, and they form the basis of this study.

ACC sizes were available in all cases except two. The mean size was $132 \mathrm{~mm}$ (range: 35-330; median: 130). Patients were classified as stage I in 2 cases, stage II in 32 cases, stage III in 7 cases, stage IV in 21 cases, and unknown stage in 2 cases (unknown size of ACC and no distant metastases). Among patients with stage IV disease, 11 disclosed more than one site of distant metastases.

Fifty-eight patients had undergone $\mathrm{OA}$, and six underwent an LA. The two patients with unknown primary tumor size underwent OA. LA was performed by five different surgeons in five hospitals, and $\mathrm{OA}$ was performed by 46 different surgeons in 41 hospitals. A lymph node dissection was performed in 16 cases. Mean size of the tumors treated with LA was $69 \mathrm{~mm}$ (range: 35-90; median 70), and mean size of the tumors treated with OA was $137 \mathrm{~mm}$ (range: 40-330; median: 140) $(P=0.006)$. Tumors treated with LA were stage II in five cases and stage IV in one case. In this last case, lung and bone metastases were diagnosed postoperatively, which explains why LA was performed despite a stage IV tumor. Tumors treated with OA were stage I in 2 cases, stage II in 27 cases, stage III in 7 cases, stage IV in 20 cases, and unknown in 2 cases. Complete R0 surgery was achieved in 42 cases ( 5 cases of LA and 37 cases of OA).

Postoperative adjuvant external beam radiation on the adrenal bed was performed in six cases, in one case treated with LA, and in five cases with OA. 
Op'DDD was given postoperatively to 61 patients. Effective therapeutic levels of plasma op'DDD were obtained in 42 patients. Median follow-up of the cohort was 35 months (range: 1-372).

\section{PC at diagnosis and recurrence}

PC was diagnosed in 18 patients (28\%) and was asymptomatic in all cases except one (Fig. 1 and Table 1). It was present at initial diagnosis in three patients and occurred during follow-up in 15 cases. PC was part of the first recurrence of ACC in ten of these patients. Median interval of time between initial surgery and the occurrence of $\mathrm{PC}$ in these 15 patients was 20 months (range: 6-332; mean 43). PC occurring during follow-up was isolated in four cases, associated with a local recurrence only in three cases, associated with abdominal lymph nodes only in one case, associated with a local recurrence and abdominal lymph nodes in one case, and associated with multiple distant metastases in six cases.

The only factor associated with the occurrence of PC was the type of surgery (Table 2). PC occurred in four of the six patients treated with LA and in 11 of the 55 patients treated with $\mathrm{OA}$. The 4-year rate of $\mathrm{PC}$ was $67 \%$
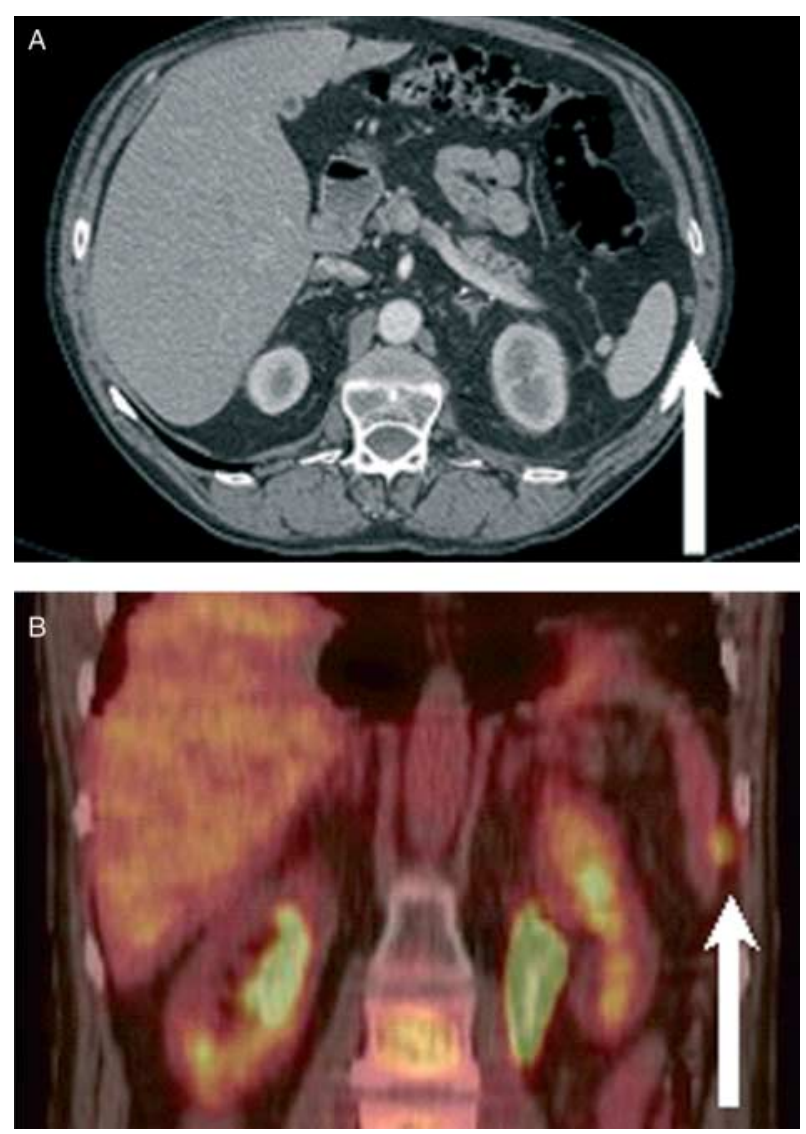

Figure $1 \mathrm{CT}(\mathrm{A})$ and $\mathrm{PET} / \mathrm{CT}(\mathrm{B})$ showing peritoneal carcinomatosis (white arrow).
(95\% CI, 30-90\%) for LA and 27\% (95\% CI, 15-44\%) for $\mathrm{OA} \quad(P=0.016$, hazard ratio $=3.8 \quad(95 \% \quad \mathrm{CI}$, 1.2-12.3)). Taking into account only patients operated with a curative intent, $\mathrm{PC}$ occurred in three of the five patients treated with LA and in 9 of the 36 patients treated with $\mathrm{OA}$. In these patients, the 4-year rate of $\mathrm{PC}$ was $60 \%$ (95\% CI, 23-88\%) for LA and 25\% (95\% CI, $13-42 \%)$ for $\mathrm{OA}(P=0.08$, hazard ratio $=3.1(95 \% \mathrm{CI}$, 0.81-11.8)).

Among patients with PC after surgery, mean size of the primary tumor was $77 \mathrm{~mm}$ (range: 70-90; median 75 ) for the four patients treated with LA and $135 \mathrm{~mm}$ (range: 50-250; median 145) for the 11 patients treated with OA. The two patients treated with LA without PC during follow-up had initial primary tumors of 35 and $70 \mathrm{~mm}$ respectively. Median interval of time between initial surgery and diagnosis of PC was 20 months (range: 16-22; mean 20 months) for the four patients treated with LA and 20 months (range: 6-332; mean 52) for the 11 patients treated with OA.

Among the six patients who underwent adjuvant postoperative external beam radiation, PC occurred in one patient treated with LA and did not occur in the five patients treated with OA. Overall, op'DDD effective therapeutic levels were obtained in four $(67 \%)$ of the patients treated with LA and $38(69 \%)$ of the patients treated with OA. Among the 15 patients who disclosed PC during follow-up, plasma op'DDD levels reached the therapeutic target in $10(67 \%)$ patients. However, the therapeutic level was reached before the occurrence of PC in only six patients. Among patients who did not disclose PC, plasma op'DDD levels reached the therapeutic target in 32 (69\%).

Ten of the 15 patients $(67 \%)$ with PC occurring during follow-up died. They had been treated with LA in three cases and with $\mathrm{OA}$ in seven cases. The median survival after the diagnosis of PC was 32 months (range: 1-47), being 5 months (range: 4-6) for patients treated with LA and 38 months for patients treated with OA (range: 1-47).

Furthermore, the 1- and 2-year local relapse-free survivals were 33 and $66 \%$ respectively in patients treated with LA, and 10 and $28 \%$ respectively in patients treated with $\mathrm{OA}(P=0.07)$.

\section{Discussion}

ACC is a rare disease with a poor prognosis mainly depending on stage and quality of initial surgery. The five-year survival ranges from 16 to $60 \%$, but is close to $35 \%$ in most studies $(4,25-32)$. Surgery (in patient with localized disease or limited resectable distant metastases) is the only potentially curative treatment $(4,27,33)$. Recurrence however occurs in 37-87\% of the patients $(27,28,33)$. They most often consist of distant metastases and less frequently of local recurrence only $(28,29,33)$. All efforts should therefore be 


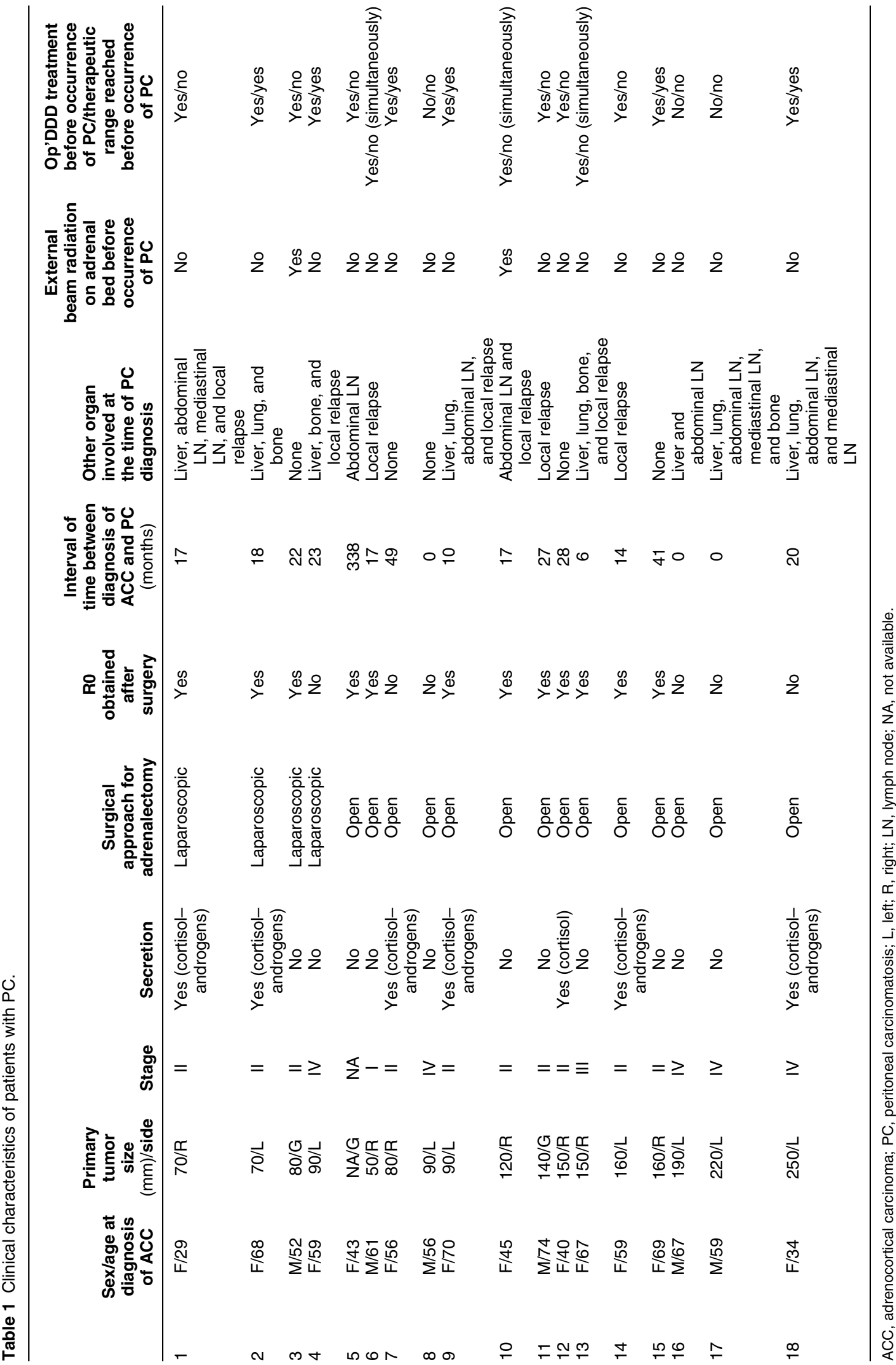


Table 2 Predicting factors of peritoneal carcinomatosis (PC) occurrence.

\begin{tabular}{llll}
\hline & $\boldsymbol{n}$ & $\begin{array}{c}\text { 4-year } \\
\text { PC rate }\end{array}$ & $\begin{array}{c}\boldsymbol{P} \\
\text { (log-rank test) }\end{array}$ \\
\hline $\begin{array}{l}\text { Surgery } \\
\text { Laparoscopic adrenalectomy }\end{array}$ & 6 & $66.7 \%$ & \\
$\quad$ Open adrenalectomy & 55 & $26.8 \%$ & 0.016 \\
Size & & & \\
$\leq 5 \mathrm{~cm}$ & 3 & $33.3 \%$ & \\
$5-10 \mathrm{~cm}$ & 21 & $43.8 \%$ & \\
$>10 \mathrm{~cm}$ & 35 & $31.1 \%$ & 0.97 \\
Stage at initial diagnosis & & & \\
I & 2 & $50.0 \%$ & \\
II & 32 & $38.2 \%$ & \\
III & 7 & $16.7 \%$ & \\
IV & 18 & $20.0 \%$ & 0.75 \\
Complete surgery (R0) & 42 & $29.3 \%$ & \\
Incomplete surgery & 19 & $46.7 \%$ & 0.94 \\
Secretion & 35 & $29.9 \%$ & \\
No secretion & 26 & $34.6 \%$ & 0.66 \\
Therapeutic plasma op'DDD & & $\mathrm{N} / \mathrm{a}^{*}$ & $0.55^{\star *}$ \\
Obtained & 42 & & \\
Not obtained & 19 & & \\
\hline
\end{tabular}

${ }^{*} \mathrm{~N} /$ a because therapeutic plasma op'DDD is a time-dependent variable. ${ }^{* *}$ Cox model with time-dependent variable.

made to perform a complete initial surgery. Owing to the scarcity of ACC, the high frequency of adrenal incidentaloma, the absence of absolute preoperative criteria of malignancy, and the increased quality of life brought by LA, a shift is being made toward minimally invasive surgery of adrenal tumors, including malignant tumors $(14-16,19,34)$. These studies however only included a limited number of ACC patients.

In this retrospective study, we found a $5 \%$ incidence of PC at diagnosis and a $25 \%$ incidence of PC during follow-up, which is much higher than previously reported (1-4). This figure might simply be related to the focus brought on PC in this study and also to the use of FDG-PET/CT in some patients. PC did not occur preferentially at the port sites. This does not preclude the technical approach from taking part into the increased risk of PC. Insufflations performed during LA may allow fluid movements and cell dispersion in the peritoneal cavity.

We found that the surgical approach was the only significant factor associated with PC: with a 4-year PC recurrence rate of $67 \%$ in patients treated with LA and $27 \%$ in patients treated with OP. These results are in accordance with those of Gonzales et al. (5). We also found a tendency toward a higher risk of local recurrence after LA compared with OA. Of course, our study is limited by the low number of ACC patients who underwent LA. But since this approach is not routinely recommended in such patients, we could not expect a large number of patients. Even taking only into account patients treated with RO complete surgery, the occurrence of $\mathrm{PC}$ was more frequent in patients treated with
LA. The difference was not statistically significant, but we are limited by the low number of patients treated with LA. A second limitation of this study is that patients were essentially referred to our center for postoperative follow-up and treatment either for recurrence or for high risk of recurrence. The number of patients treated successfully by LA or OA is in fact unknown precluding the determination of the true risk factor of PC in ACC.

We were not able to distinguish the risk of PC due to an inappropriate surgical approach from the risk of ACC due to difficult surgery or surgery performed in nonexperienced centers. The avoidance of tumor capsular rupture during surgery is, in fact, mandatory in ACC treatment, and is both dependent of tumor characteristics and surgeon skill. However, none of the surgical reports of LA mentioned tumor rupture. Furthermore, both OA and LA were performed in various centers. In the literature, besides the study from Gonzalez et al. (5), only one retrospective study did not observe an increase in PC after LA of adrenal malignancies (16). They however did not compare open surgery to laparoscopic surgery, and only included four ACC patients among whom one needed a conversion to an open procedure and one developed a pelvic 18-cm recurrence 6 months after initial surgery that was compatible with PC. Of note, clinical cases of $\mathrm{PC}$ occurring in ACC patients after LA were recently reported (35-37).

Tumors operated with LA were smaller than those operated with OA (mean size 69 vs $137 \mathrm{~mm}$ ) but disclosed more often PC. Interestingly, the smallest tumor which disclosed PC had a 50-mm diameter, and was operated through an OA. These results suggest that the risk of PC is not limited to large tumors, and that caution should be applied to adrenal tumors bearing suspicious preoperative features of malignancy at imaging, including size, elevated spontaneous density on CT scan, contrast enhancement in tumor with spontaneous density above 10UH, presence of lymphadenopathy, and FDG uptake $(38,39)$.

Strikingly, one-third of the PC observed during followup was isolated suggesting that avoiding PC would be a major issue in patients with ACC whether operated through a LA or an OA. Furthermore, in $20 \%$ of other cases, PC was only associated with a local recurrence which might have been resectable. Intraperitoneal rupture of the primary tumor causing tumor spillage during surgery is indeed a major cause of PC. In our study, surgery was performed by many surgeons, and the occurrence of PC was not associated with a particular surgeon.

Whether PC has an impact on prognosis remains to be proven. PC is indeed regarded as a lethal entity. However, the hypothesis that ACC recurrence is a major prognostic event is reasonable. Indeed, the first recurrence is known to be highly predictive for further recurrences with a shorter interval of time between recurrences (40). Of note, in our study, the 
median interval of time between initial surgery and the occurrence of PC was 20 months, similar in patients treated with LA or OA and close to the median 10-30 months reported median time between initial surgery and first recurrence $(1,29,31,33,40,41)$.

In conclusion, our results suggest that there may be an increased risk of PC after laparoscopic surgery of malignant ACC. Whether the increased risk of PC is related to an inappropriate surgical approach or to insufficient experience in ACC surgery should to be clarified by prospective program set up by international ACC network.

\section{Declaration of interest}

The authors declare that there is no conflict of interest that could be perceived as prejudicing the impartiality of the research reported.

\section{Funding}

This research did not receive any specific grant from any funding agency in the public, commercial, or not-for-profit sector.

\section{Acknowledgements}

The authors are indebted to Catherine Martin for secretarial assistance.

\section{References}

1 Pommier RF \& Brennan MF. An eleven-year experience with adrenocortical carcinoma. Surgery 1992112 963-970. discussion 970-1.

2 Evans HL \& Vassilopoulou-Sellin R. Adrenal cortical neoplasms. A study of 56 cases. American Journal of Clinical Pathology 1996105 76-86.

3 Assie G, Antoni G, Tissier F, Caillou B, Abiven G, Gicquel C, Leboulleux S, Travagli JP, Dromain C, Bertagna X, Bertherat J, Schlumberger M \& Baudin E. Prognostic parameters of metastatic adrenocortical carcinoma. Journal of Clinical Endocrinology and Metabolism 200792 148-154.

4 Bilimoria KY, Shen WT, Elaraj D, Bentrem DJ, Winchester DJ, Kebebew E \& Sturgeon C. Adrenocortical carcinoma in the United States: treatment utilization and prognostic factors. Cancer 2008 113 3130-3136.

5 Gonzalez RJ, Shapiro S, Sarlis N, Vassilopoulou-Sellin R, Perrier ND, Evans DB \& Lee JE. Laparoscopic resection of adrenal cortical carcinoma: a cautionary note. Surgery $2005 \mathbf{1 3 8}$ 1078-1085. discussion 1085-6.

6 Gagner M, Lacroix A \& Bolte E. Laparoscopic adrenalectomy in Cushing's syndrome and pheochromocytoma. New England Journal of Medicine 19923271033.

7 Bonjer HJ, Lange JF, Kazemier G, de Herder WW, Steyerberg EW \& Bruining HA. Comparison of three techniques for adrenalectomy. British Journal of Surgery $1997 \mathbf{8 4} 679-682$.

8 Thompson GB, Grant CS, van Heerden JA, Schlinkert RT, Young WF Jr, Farley DR \& Ilstrup DM. Laparoscopic versus open posterior adrenalectomy: a case-control study of 100 patients. Surgery 1997122 1132-1136.

9 Dudley NE \& Harrison BJ. Comparison of open posterior versus transperitoneal laparoscopic adrenalectomy. British Journal of Surgery 199986 656-660.

10 Imai T, Kikumori T, Ohiwa M, Mase T \& Funahashi H. A casecontrolled study of laparoscopic compared with open lateral adrenalectomy. American Journal of Surgery 1999178 50-53. discussion 54
11 Gonzalez R, Smith CD, McClusky DA III, Ramaswamy A, Branum GD, Hunter JG \& Weber CJ. Laparoscopic approach reduces likelihood of perioperative complications in patients undergoing adrenalectomy. American Surgeon 200470 668-674.

12 Grumbach MM, Biller BM, Braunstein GD, Campbell KK, Carney JA, Godley PA, Harris EL, Lee JK, Oertel YC, Posner MC, Schlechte JA \& Wieand HS. Management of the clinically inapparent adrenal mass ("incidentaloma"). Annals of Internal Medicine 2003138 424-429.

13 Allolio B \& Fassnacht M. Clinical review: adrenocortical carcinoma: clinical update. Journal of Clinical Endocrinology and Metabolism 200691 2027-2037.

14 Heniford BT, Arca MJ, Walsh RM \& Gill IS. Laparoscopic adrenalectomy for cancer. Seminars in Surgical Oncology 1999 16 293-306.

15 Henry JF, Sebag F, Iacobone M \& Mirallie E. Results of laparoscopic adrenalectomy for large and potentially malignant tumors. World Journal of Surgery 200226 1043-1047.

16 Lombardi CP, Raffaelli M, De Crea C \& Bellantone R. Role of laparoscopy in the management of adrenal malignancies. Journal of Surgical Oncology 200694 128-131.

17 Kirshtein B, Yelle JD, Moloo H \& Poulin E. Laparoscopic adrenalectomy for adrenal malignancy: a preliminary report comparing the short-term outcomes with open adrenalectomy. Journal of Laparoendoscopic \& Advanced Surgical Techniques. Part A $20081842-46$.

18 Parnaby CN, Chong PS, Chisholm L, Farrow J, Connell JM \& O'Dwyer PJ. The role of laparoscopic adrenalectomy for adrenal tumours of $6 \mathrm{~cm}$ or greater. Surgical Endoscopy 200822 617-621.

19 Soon PS, Yeh MW, Delbridge LW, Bambach CP, Sywak MS, Robinson BG \& Sidhu SB. Laparoscopic surgery is safe for large adrenal lesions. European Journal of Surgical Oncology 200834 $67-70$.

20 Cobb WS, Kercher KW, Sing RF \& Heniford BT. Laparoscopic adrenalectomy for malignancy. American Journal of Surgery 2005 189 405-411.

21 Leboulleux S, Dromain C, Bonniaud G, Auperin A, Caillou B, Lumbroso J, Sigal R, Baudin E \& Schlumberger M. Diagnostic and prognostic value of 18 -fluorodeoxyglucose positron emission tomography in adrenocortical carcinoma: a prospective comparison with computed tomography. Journal of Clinical Endocrinology and Metabolism 200691 920-925.

22 Fassnacht M, Johanssen S, Quinkler M, Bucsky P, Willenberg HS, Beuschlein F, Terzolo M, Mueller HH, Hahner S \& Allolio B. Limited prognostic value of the 2004 International Union Against Cancer staging classification for adrenocortical carcinoma: proposal for a Revised TNM Classification. Cancer 2009115 243-250.

23 Dromain C, Leboulleux S, Auperin A, Goere D, Malka D, Lumbroso J, Schumberger M, Sigal R \& Elias D. Staging of peritoneal carcinomatosis: enhanced CT vs. PET/CT. Abdominal Imaging 200833 87-93.

24 Rothman KJ. Estimation of confidence limits for the cumulative probability of survival in life table analysis. Journal of Chronic Diseases 197831 557-560.

25 Henley DJ, van Heerden JA, Grant CS, Carney JA \& Carpenter PC. Adrenal cortical carcinoma - a continuing challenge. Surgery $198394926-931$.

26 Barzon L, Fallo F, Sonino N, Daniele O \& Boscaro M. Adrenocortical carcinoma: experience in 45 patients. Oncology 199754 490-496.

27 Schulick RD \& Brennan MF. Long-term survival after complete resection and repeat resection in patients with adrenocortical carcinoma. Annals of Surgical Oncology 19996 719-726.

28 Icard P, Goudet P, Charpenay C, Andreassian B, Carnaille B, Chapuis Y, Cougard P, Henry JF \& Proye C. Adrenocortical carcinomas: surgical trends and results of a 253-patient series from the French Association of Endocrine Surgeons study group. World Journal of Surgery 200125 891-897. 
29 Kendrick ML, Lloyd R, Erickson L, Farley DR, Grant CS, Thompson GB, Rowland C, Young WF Jr \& van Heerden JA. Adrenocortical carcinoma: surgical progress or status quo? Archives of Surgery $2001136543-549$.

30 Vassilopoulou-Sellin R \& Schultz PN. Adrenocortical carcinoma. Clinical outcome at the end of the 20th century. Cancer 200192 1113-1121.

31 Stojadinovic A, Ghossein RA, Hoos A, Nissan A, Marshall D, Dudas M, Cordon-Cardo C, Jaques DP \& Brennan MF. Adrenocortical carcinoma: clinical, morphologic, and molecular characterization. Journal of Clinical Oncology 200220 941-950.

32 Abiven G, Coste J, Groussin L, Anract P, Tissier F, Legmann P, Dousset B, Bertagna X \& Bertherat J. Clinical and biological features in the prognosis of adrenocortical cancer: poor outcome of cortisol-secreting tumors in a series of 202 consecutive patients. Journal of Clinical Endocrinology and Metabolism 2006 $912650-2655$.

33 Bellantone R, Ferrante A, Boscherini M, Lombardi CP, Crucitti P, Crucitti F, Favia G, Borrelli D, Boffi L, Capussotti L, Carbone G, Casaccia M, Cavallaro A, Del Gaudio A, Dettori G, Di Giovanni V, Mazziotti A, Marrano D, Masenti E, Miccoli P, Mosca F, Mussa A Petronio R, Piat G, Ruberti U, Sergio G \& Marazano L. Role of reoperation in recurrence of adrenal cortical carcinoma: results from 188 cases collected in the Italian National Registry for Adrenal Cortical Carcinoma. Surgery $19971221212-1218$.

34 Kebebew E, Siperstein AE, Clark OH \& Duh QY. Results of laparoscopic adrenalectomy for suspected and unsuspected malignant adrenal neoplasms. Archives of Surgery 2002137 948-951. discussion 952-3.

35 Ushiyama T, Suzuki K, Kageyama S, Fujita K, Oki Y \& Yoshimi T. A case of Cushing's syndrome due to adrenocortical carcinoma with recurrence 19 months after laparoscopic adrenalectomy. Journal of Urology 19971572239.
36 Hamoir E, Meurisse M \& Defechereux T. Is laparoscopic resection of a malignant corticoadrenaloma feasible? Case report of early, diffuse and massive peritoneal recurrence after attempted laparoscopic resection. Annales de Chirurgie 199852 364-368.

37 Foxius A, Ramboux A, Lefebvre Y, Broze B, Hamels J \& Squifflet J. Hazards of laparoscopic adrenalectomy for Conn's adenoma. When enthusiasm turns to tragedy. Surgical Endoscopy 199913 715-717.

38 Boland GW, Lee MJ, Gazelle GS, Halpern EF, McNicholas MM \& Mueller PR. Characterization of adrenal masses using unenhanced CT: an analysis of the CT literature. AJR. American Journal of Roentgenology $1998 \mathbf{1 7 1} 201-204$.

39 Groussin L, Bonardel G, Silvera S, Tissier F, Coste J, Abiven G, Libe R, Bienvenu M, Alberini JL, Salenave S, Bouchard P, Bertherat J, Dousset B, Legmann P, Richard B, Foehrenbach H, Bertagna X \& Tenenbaum F. ${ }^{18}$ F-Fluorodeoxyglucose positron emission tomography for the diagnosis of adrenocortical tumors: a prospective study in 77 operated patients. Journal of Clinical Endocrinology and Metabolism 200994 1713-1722.

40 Tauchmanova L, Colao A, Marzano LA, Sparano L, Camera L, Rossi A, Palmieri G, Marzano E, Salvatore M, Pettinato G, Lombardi G \& Rossi R. Andrenocortical carcinomas: twelve-year prospective experience. World Journal of Surgery $2004 \mathbf{2 8}$ 896-903.

41 Gicquel C, Bertagna X, Gaston V, Coste J, Louvel A, Baudin E, Bertherat J, Chapuis Y, Duclos JM, Schlumberger M, Plouin PF, Luton JP \& Le Bouc Y. Molecular markers and long-term recurrences in a large cohort of patients with sporadic adrenocortical tumors. Cancer Research $2001616762-6767$.

Received 24 February 2010

Accepted 25 March 2010 